\title{
La renovación de la lingüística en Argentina: un estudio histórico y epistemológico de la colección Lengua-Lingüística-Comunicación de la editorial Hachette
}

\author{
Federico Ternavasio ${ }^{\bullet}$ \\ Universidad Nacional del Litoral
}

\begin{abstract}
Resumen
Nuestro trabajo pretende reconstruir un episodio reciente de la historia de la lingüística en Argentina a partir de indagar un objeto específico: los tomos de la colección Lengua-Lingüística-Comunicación que la editorial Hachette publicó entre 1979 y 1989, en tanto aportes sustanciales para la renovación de los estudios sobre el lenguaje en el país, durante los años finales de la última dictadura cívico-militar y en el transcurso de la década del ochenta (Rubio Scola, 2014:69). Teniendo en cuenta que en la colección se incorporan títulos de estudios literarios, teoría semiótica y psicoanálisis, nos centramos solamente en aquellos volúmenes que se inscriben explícitamente en el marco de la lingüística.

Siguiendo la hipótesis de que de la colección emerge una propuesta programática para la renovación de la teoría lingüística, analizamos el modo en que cada texto construye ese programa desde su propia textualidad, a la vez que pensamos cómo «actúa» su publicación en el contexto argentino, partiendo del marco teórico de los actos de habla, en el sentido de Skinner (2007). Concebidas en otra lengua y en circunstancias distintas a las de la Argentina de los '70 y ' 80 , las teorías presentadas en los volúmenes de la colección encuentran una nueva operatividad al publicarse en nuestro país, por lo que otro interés de nuestro trabajo es problematizar, siguiendo la propuesta de Edward Said, el modo en que las teorías circulan o «viajan».

\section{Palabras clave:}

colección Hachette · historia de la Lingüística · migraciones teóricas
\end{abstract} 250251

\footnotetext{
- Estudiante avanzado de la carrera de Licenciatura en Letras. Desde agosto de 2014 hasta agosto de 2015, bajo una beca «Estímulo a las Vocaciones Científicas» del Consejo Interuniversitario Nacional, comienza a trabajar en el marco del proyecto «Régimen epistémico, instituciones y disciplina: un estudio CTS de las actividades científicas y tecnológicas en Argentina. Período 1940-1980», donde realiza la presente investigación, que actualmente continúa como adscripción en la cátedra de Epistemología e Historia de la Lingüística y como trabajo de tesina.
} 


\begin{abstract}
Our work pretends to rebuild a recent episode in the history of linguistics in Argentina, starting from inquiring a specific object: the volumes of the collection Lengua-Lingüística-Comunicación that Hachette published between 1979-1989, as substantial contributions to the renewal of language studies in the country during the final years of the last civic-military dictatorship and the eighties (Rubio Scola 2014:69).

Given that the collection incorporates titles of literary studies, semiotic theory and psychoanalysis, we focus only in those volumes that inscribes explicitly in the framework of linguistics. Following the hypothesis that of the collection emerge the proposition of a program for the renewal of linguistic theory, we analyze how the texts built that program from its own textuality, while we think how does its publication in the Argentine context «acts», starting from the theoretical framework of speech acts, in the sense of Skinner (2007).

Conceived in another language and in different circumstances from the Argentina of the seventies and eighties, the theories presented in the volumes of the collection found a new operativity when they are published in our country, so another interest of our work is to discuss, following the proposal of Edward Said, how theories circulate or «travel».
\end{abstract}

\title{
Key words:
}

collection Hachette · history of linguistics · theories migration

\section{1.}

Desde 1979 bajo la editorial Hachette y hasta 2002 cuando ésta pasa a ser Edicial, se publica, como una subdivisión de la serie Hachette Universidad, el catálogo de la colección Lengua-Lingüística-Comunicación (en adelante LLC). Quien lo dirige es Elvira Narvaja de Arnoux, lingüista argentina que en un período de exilio en Francia logra un acuerdo con la embajada para publicar los títulos en nuestro país.

Como explica Arnoux en entrevista con Rubio Scola (2014), durante los años en que coincide la publicación de los títulos con la dictadura, no hubo interferencias directas de la censura: «probablemente por el peso de la editora francesa y porque se trataba de textos específicos en los que para comprender en algunos de ellos la posición ideológica se necesitaban conocimientos del área» (115). 
Sin embargo podemos identificar cierto cuidado político en la publicación si se atiende a que, en los libros, cuando se consignan los datos de la directora, no figura el apellido Narvaja, que podría haber sido vinculado a Fernando Vaca Narvaja y la organización Montoneros.

Los títulos que componen la colección LLC pueden agruparse en dos series, por un lado los textos traducidos del francés y por el otro los producidos en nuestro país. Los primeros son trabajos que tenían como máximo cuatro años de publicados en su versión original, y se publican con la intención de poner en circulación las últimas novedades teóricas producidas en Francia.

Los textos producidos en Argentina, como señala Arnoux (Rubio Scola, 2014), se publican con el objetivo de «divulgar trabajos nacionales», es decir, dar visibilidad a las investigaciones en lingüística que se estaban desarrollando en las universidades del país, y a un mismo nivel de legitimidad que los desarrollos de un centro de producción como el europeo.

Estos textos de locales posibilitan pensar, en cierta medida, cómo se fue transformando el modo en que se hacía lingüística en nuestro país durante esos años. Si a modo de ejemplo confrontamos algunos de los títulos de la colección, como son Estudios lingüísticos y dialectológicos de 1979, Variación y significado de 1984, y La gramática modular de 1989, vemos cómo se da paso de una lingüística ecléctica a una lingüística de fuertes compromisos teóricos. A la vez, de esos títulos se pueden desagregar distintos programas para la lingüística, cada uno con un modo diferente de relación con el objeto lengua o lenguaje, y en directa relación con los marcos con los que se comprometen las autoras.

El primero de los volúmenes que mencionamos reúne, en primer lugar, cinco artículos de Ana María Barrenechea, sea como única autora o como coautora, pero siempre en la línea de su estilo de trabajo. Podemos caracterizar ese estilo, siguiendo a Menéndez (2013), a partir de tres constantes presentes a lo largo de toda la producción de la lingüista: el textualismo, es decir, el texto como unidad de análisis privilegiada; la complementariedad de la relación forma/significado sin la supremacía de un elemento sobre el otro; y la importancia del rol del hablante en el estudio sobre el lenguaje.

En los textos de Barrenechea presentes en el volumen no hay compromisos teóricos fuertes con ningún marco reconocible, se utilizan categorías provenientes de distintas tradiciones de un modo aplicativo, sin explicitar tampoco un modelo teórico propio que las organice. Son textos descriptivos, sin hipótesis explicativas, que utilizan entrevistas para realizar estadísticas de preferencias del uso de los hablantes o bien como evidencia para determinar un tipo de análisis gramatical.

Podemos ver algunas de esas características mencionadas, concretamente, cuando en el capítulo dos del volumen, titulado «A propósito de la elipsis en la coordinación», Barrenechea presenta las categorías que va a utilizar en su trabajo:

al referirnos a los textos emitidos por el hablante, usaremos los nombres de «nivel» o «estructura de superficie», sin que eso implique aceptar la existencia de una estructura profunda; también emplearemos indistintamente la terminología transformacionalista de «conjunción de oraciones» o la tradicional de elipsis. (1979:21)

Podemos ilustrar también las características mencionadas citando un fragmento donde, a modo de conclusión del capítulo, la autora realiza una apreciación vinculada al hacer del lingüista que también es relevante transcribir: 
Si no es esa su meta [caracterizar una competencia lingüística] como no es la nuestra, creemos que metodológicamente [el lingüista] debe emplear el concepto de elipsis sólo en los casos en que es indispensable preservar a la vez ese núcleo significativo y las convenciones estructurales mínimas exigidas por la lengua estudiada, es decir, por su sistema de pautas sintácticas. (35)

Como se ve, la conclusión apunta no a determinar qué relación se establece finalmente entre las coordinaciones, los posibles niveles estructurales y la elipsis, sino más bien a recomendar un uso del concepto de elipsis para los lingüistas. Ese modo de uso, además, apunta a que se aplique el concepto cuando es necesario "preservar» las convenciones estructurales atribuidas a una lengua, y no en otros casos, aunque no está claro qué habilita ese uso y qué no habilita el uso generalizado.

En el mismo volumen se publican, además de los textos de Barrenechea, un texto de María Luisa Freyre que discute brevemente la asignación de caso dativo "puramente sintáctica» propuesta por el generativismo. Y finalmente un texto de Clara Wolf y Elena Jimenez cierra el volumen con un estudio de caso titulado «El ensordecimiento del yeísmo porteño, un cambio fonológico en marcha», que es un trabajo articulado dentro del marco de la sociolingüística de Labov y los aportes de Beatriz Lavandera.

En esos dos últimos capítulos sí se puede reconocer un marco teórico con el cual las autoras se relacionan. En el caso de Freyre, se formula una crítica interna a las categorías propias del generativismo, mientras que Wolf y Jiménez asumen las metodologías y los objetivos del marco de Labov, vinculando las conclusiones que extraen de su estudio con las hipótesis de dicho lingüista norteamericano (Wolf y Jiménez, 1979:116).

Por lo tanto, tenemos que, como un volumen que recupera aportes de distintos autores, se nos presentan distintas imágenes de lo que es el trabajo del lingüista. Es difícil pensar, a partir de los textos de Barrenechea, un programa concreto de trabajo para la lingüística, cuando los mismos aportes realizados al volumen, más allá de que evidencian la gran intuición lingüística de la autora, son aislados y no se articulan explícitamente con hipótesis más amplias sobre el lenguaje; mientras que en el caso Freyre por un lado, y Wolf y Jiménez por el otro, podemos ver que las hipótesis planteadas están dentro de un programa científico más amplio que las autoras, sea el generativismo o la sociolingüística cualitativa.

El tomo de 1984, Variación y significado, de Beatriz Lavandera, recopila distintos trabajos de la autora que se agrupan por problemáticas: el estudio de la variación, el bilingüismo, la lingüística del discurso y la lingüística romance. Aquí hay un programa explícito de trabajo, y cada texto busca realizar un aporte en vías de su concreción.

La autora es una de las claras figuras de referencia de la renovación de la teoría lingüística en Argentina, doctorada en EEUU, regresa al país con la refundación democrática a partir del gobierno de Raúl Alfonsín. Como se señala en Vallejos, Stiefel y Lammertyn:

el retorno al país de Beatriz Lavandera (...) está ligado a varios procesos que configuran un cuadro de renovación en la Lingüística local que, en términos generales, puede entenderse como el intento de institucionalizar la Lingüística como una disciplina completa y el inicio de un programa de investigación central en la Lingüística argentina: los estudios del discurso y la perspectiva funcional. (Vallejos et al., 2012:7) 
Como si se tratara de una agenda de trabajo, Lavandera remarca en los textos del volumen qué elementos de la teoría deben manifestarse claramente en la disciplina lingüística para que ésta pueda desarrollarse como una ciencia que comienza a encaminarse a su madurez, saliendo de los paradigmas que la seguían retrayendo a la filología y al lugar de las humanidades clásicas (Lavandera, 1984:12).

Como indica el título del libro, los capítulos se van a orientar hacia dos grandes problemáticas de la lingüística, por un lado el problema de la variación y el cambio en las lenguas (estilo de trabajo al que adscribe el texto de Wolf y Jiménez ya comentado), y por otro el problema del significado, abordado desde una perspectiva anclada entre el funcionalismo y la sociolingüística.

Aunque Lavandera da cuenta de los marcos teóricos en los que trabaja, no debe entenderse que la autora emprende una tarea de «presentación» de esos marcos en el país. Si bien en la introducción se hace referencia a los últimas corrientes teóricas surgidas a nivel internacional, los textos se limitarán al estudio de casos problemáticos dentro de cada área, con excepción de la parte final del libro, que bajo el subtítulo de «Sociolingüística romance», se propone presentar una reseña bibliográfica general del campo de la sociolingüística (Lavandera, 1984:158), con el objetivo de actualizar una bibliografía luego de un período de cerrazón del mercado editorial.

Podemos ejemplificar ese programa de renovación de Lavandera con un fragmento de la introducción al volumen:

Teórica y metodológicamente, entonces, la primera tarea del lingüista pasa a ser establecer con claridad cuál es el conjunto de los hechos que requiere una explicación esencialmente «lingüística», qué tipo de «explicaciones» pueden darse de tales hechos, con qué métodos pueden «validarse» tales explicaciones, y cuál es la relación con el resto de la descripción y explicación de la actividad humana de la que el lenguaje es parte definitoria. (12)

Como vemos, Lavandera propone operaciones que hacen reflexiva las operaciones epistemológicas de la lingüística: delimitar el objeto, explicitar qué tipo de hipótesis se realizarán respecto a él, cómo se probarán esas hipótesis y qué tipo de pruebas se considerarán válidas. Por otra parte, la autora también llama a preguntarse qué relaciones externas va a establecer la lingüística, cómo va a interactuar con respecto a las ciencias colindantes.

Hay que destacar que la reflexión epistemológica como la propone Lavandera se presenta como parte primera de la tarea del lingüista, como algo interno a la disciplina y no como una mirada externa. Es un tipo de reflexión que todavía sigue siendo tema de discusión (Cf. Swiggers, 2009).

Para finalizar con esta breve comparación de los volúmenes producidos localmente, tomaremos La gramática modular, de Nora Múgica y Zulema Solana, publicado en 1989. Este libro va a ser directamente de articulación de una teoría dominante a nivel internacional para un público de habla hispana con cierto grado de especialización en el área. En ese sentido, la propuesta de las autoras es explicar los postulados de la gramática generativa utilizando la lengua hablada en nuestro país como objeto.

Se presentará, en el volumen, un recorrido por las principales categorías utilizadas en el marco generativista de principios y parámetros: categorías sintácticas, categorías léxicas, categorías vacías; además de problematizar los distintos componentes teóricos del modelo: teoría de rección, teoría del caso, teoría de la referencia, teoría de ligamiento, de control, de los roles temáticos y principio de proyección. 
A diferencia de la propuesta de Lavandera, donde a pesar de la pertenencia a ciertos marcos teóricos la propuesta programática era independiente, en este volumen el programa que emerge se identifica completamente con el programa del generativismo, como señalan las mismas autoras en la introducción:

La Teoría Lingüística dentro de cuyo marco nos movemos busca caracterizar y explicar el conocimiento del lenguaje, su naturaleza, origen y uso; y las preguntas básicas que se plantean constituyen un verdadero programa de investigación: 1. ¿Qué constituye el conocimiento del lenguaje?; 2. ¿Cómo se adquiere este conocimiento?; 3 . ¿Cómo se usa este conocimiento? (Múgica y Solana, 1989:19)

Es interesante ver cómo hay plena conciencia de la adscripción a ese programa e inclusive se modaliza sobre esa propuesta, identificando que es un programa «verdadero». Las autoras, enfatizan además que, si se toma el camino de la gramática generativa, la lingüística se acercaría a la psicología y a la biología, como ciencia cognitiva, siempre y cuando se preocupe por el estudio del conocimiento del lenguaje que tiene un hablante. Es decir, se hace foco en caracterizar esa "competencia lingüística» que Barrenechea diez años atrás, como citábamos anteriormente, no se comprometía a indagar.

\section{2.}

Como señalábamos en la introducción, nuestro trabajo se fundamenta en el presupuesto de que es posible abordar la colección LLC como un documento que da cuenta de un programa para la renovación de la teoría lingüística en el país.

Pudimos ver que, en los volúmenes producidos localmente, hay una transformación del modo en que se concebía el hacer del lingüista, según se asumiera o no el compromiso con un marco teórico, y si ese marco era una construcción propia o era un modelo producido en el exterior al que se adscribía.

Para ese primer objetivo recurrimos al análisis de textos, observando las relaciones internas a cada uno de los volúmenes. Más allá de los fragmentos concretos que reproducimos como un modo de mostrar propuestas programáticas, es importante señalar que cada uno de los libros tiene una riqueza conceptual que excede ampliamente lo que aquí analizamos.

Ahora bien, las propuestas programáticas citadas apuntaban mayormente a intervenir en el campo disciplinar, es decir, eran textos pensados para lingüistas o estudiantes de lingüística.

Es también nuestro objetivo poder pensar cómo se relacionan los volúmenes de la colección «hacia afuera» de la disciplina. Para abordar estas cuestiones nuestra reflexión parte desde el marco de los «actos de habla».

Fundamentalmente, lo que interesa del marco mencionado es que habilita pensar la «intencionalidad» como una "fuerza ilocutiva» particular, de lo que en este caso es un «macro acto de habla», es decir, la publicación de la colección. En otras palabras, la categoría nos ayuda a nombrar ese potencial de efectos, en determinado momento histórico, que encierra el poner a circular ciertas ideas en forma de textos.

A la vez, si consideramos a la colección como un macro acto de habla, podemos 
incorporar la dimensión del contexto en el cual la publicación está actuando, es decir, está modificando el estado de cosas. Dentro de la colección, el grupo de textos traducidos, viene a establecer una relación mucho más evidente que los textos locales, de esto que llamamos la actuación de la publicación en el contexto. Sin embargo, esto plantea un problema: el modo en que operan los textos en el contexto de los setenta y ochenta en Argentina, difícilmente haya estado previsto como parte de esa intencionalidad de los autores y autoras que los produjeron.

Para conceptualizar esa problemática recuperamos la concepción de Edward Said (2004) de la "teoría ambulante» o «viajera». Partiendo de una propuesta que intenta entender a las teorías no como un elemento estático ni como parte de un plano diferente al de los asuntos del mundo, Said aborda las preguntas de qué le sucede a una teoría cuando «en diferentes circunstancias y por nuevas razones, se utiliza una y otra vez, en circunstancias aún más distintas», y procura analizar "qué puede revelarnos esto acerca de la propia teoría» (Said, 2004:308).

Este viaje de las teorías atraviesa, según Said, distintos momentos: primero hay un origen, posiblemente aparente, que da lugar al nacimiento de una idea como consecuencia de determinadas condiciones históricas; luego esa idea atraviesa una distancia temporal o espacial, donde toma nueva relevancia; en un tercer momento la teoría alcanza aceptación y resistencias, es tolerada y reintroducida en el discurso; finalmente toma posición en un nuevo conjunto de condiciones, transformada por la presión de los contextos que atravesó. Creemos que algo similar ocurre con las teorías de los textos traducidos.

Hay una primera circunstancia que significa una transformación donde las teorías necesariamente se readaptan, que es el momento de la traducción y puesta en serie con otros textos - muchos también traducidos. La otra circunstancia es la situación sociopolítica en que son publicados, es decir, en los años finales de una dictadura y los primeros años de una reapertura democrática. En ese sentido, tenemos que atender a lo que «significa» la publicación de esos textos.

Tomemos por caso el texto El decir y lo dicho de Oswald Ducrot, publicado en la colección en 1984, y cuyo original se publica en Francia en 1980. A la salida de una dictadura en la que, «con el pretexto de desterrar la actividad política de la Universidad, considerada como un elemento altamente corruptor de la vida académica, se eliminaron el debate y la confrontación de ideas» (Buchbinder, 2010:209), se viene a traducir y publicar en nuestro país un texto que hace foco en el modo en que el sujeto se relaciona con el lenguaje y cómo interpela a otros sujetos con su uso, que indaga sobre el modo en que el lenguaje cifra aquello que no se dice y cómo esos elementos operan en la enunciación, y que propone pensar los significados del lenguaje en uso.

Es decir, luego de un tiempo en que la agenda de la dictadura para el lenguaje preveía una clausura de las posibilidades de debate, se viene a traducir y publicar a un autor que escribe, textualmente: «nos es forzoso concluir que la lengua, independientemente de las utilizaciones que podamos hacer de ella, se presenta fundamentalmente como el lugar del debate y de la confrontación de las subjetividades» (Ducrot, 1984:43).

Claramente, existe un contexto en el que la publicación de este tipo de reflexiones viene a actuar sobre el estado de cosas de modo que permite contrarrestar una agenda estructurada para la universidad por la dictadura.

Debe tenerse en cuenta también que en ese mismo contexto el poder político y económico buscaba construir, mediante los medios de comunicación masivos, una 
«atmósfera de normalidad» (Sirlin, 2008:400), es decir, desde la llamada «prensa gris» (los medios que no eran directamente apologéticos pero tampoco confrontaban frontalmente), que «ocultó el horror, neutralizó las editoriales, impersonalizó los verbos de las acciones represivas» (ídem), se intentaba crear la sensación en el cuerpo social de que se vivía bajo una administración "normal». Frente a ese contexto, entonces, también se puede leer el volumen de Ducrot como un modo de echar luz a fenómenos de manipulación que toman como vehículo el lenguaje, y de poner a disposición herramientas para poder desmontar esas operaciones:

La lengua ofrece así a cada interlocutor la posibilidad de encerrar al otro en un universo intelectual creado en el diálogo mismo. En estas condiciones, la polémica no es una función segunda del lenguaje, (...) al revés, se funda en la naturaleza misma del enunciado lingüístico, que pone a cada momento a disposición del locutor, bajo la forma de presupuestos, una suerte de red en la que podrá envolver a su adversario. (Ducrot, 1984:27)

Sin la toma de conciencia por parte de los lingüistas primero, y una posterior puesta en circulación de estas perspectivas sobre el lenguaje que puedan llegar a volverse parte de una ideología lingüística más o menos generalizada, es muy difícil que fenómenos como los de la manipulación mediática y política puedan comenzar a pensarse.

Otro aspecto del trabajo de Ducrot, que también estará presente en el tomo La enunciación de Kerbrat-Orecchioni, publicado en 1983 (original en francés publicado en 1977), y que tiene gran relevancia si lo vinculamos al contexto, es el modo en que se diferencian «enunciador» $\mathrm{y}$ «locutor», así como «destinatario» $\mathrm{y}$ «alocutario». Es decir, se comienza a reconocer, frente a modelos teóricos anteriores, que no siempre la responsabilidad del enunciado (el rol de enunciador) recae en quien entrega o articula el mensaje, aquel que presta la voz y toma el rol de locutor; así como no siempre quien recibe un mensaje, el destinatario, es a quien va dirigida la interpelación del mismo, es decir, el alocutario. Estos elementos habilitan pensar, por un lado la responsabilidad de los sujetos frente a sus enunciados, y por el otro, el modo en que esos enunciados pueden adoptar diferentes voces como medios de materializarse frente al cuerpo social.

Kerbrat-Orecchioni va identificar estos elementos y otros subtipos en un modelo enriquecido de la enunciación, así como también va a realizar un modelo enriquecido del clásico esquema de la comunicación de Jakobson, en el que se van a incorporar factores como la "competencia ideológica y cultural», que significarán reconocer en los sujetos presentes en toda comunicación limitaciones impuestas por «el conjunto de conocimientos implícitos que poseen sobre el mundo» $\mathrm{y}$ «el conjunto de los sistemas interpretativos y de evaluación del universo referencial» (Kerbrat-Orecchioni, 1983:28).

Como vemos en los ejemplos esbozados, efectivamente puede pensarse una actuación de la publicación de la colección en el contexto del fin de la dictadura y la vuelta a la democracia, brindando categorías y perspectivas para contrarrestar un modo de concebir el lenguaje heredado por las políticas de la junta militar, y a la vez para poder pensar el modo en que se construyeron silencios y normalizaciones mediante los medios masivos.

Hasta aquí, destacamos dos actuaciones entre algunos de los volúmenes de la colección: primero citamos los programas explícitos para la lingüística en los textos 
de producción local, y segundo, vimos cómo podía interpretarse el modo en que la publicación de los textos actúa en el contexto en que se traducen. Podríamos agregar, además, que en la colección también se construye una historia de la lingüística, orientada a legitimar los marcos teóricos que circulan en los volúmenes.

Los tomos que más explícitamente realizan esto son, primero Introducción a las problemáticas de las corrientes lingüisticas contemporáneas, de Catherine Fuchs y Pierre Le Goffic, publicado en 1979 (original francés de 1975), y que en capítulos muy breves realizará un análisis somero de la corriente estructuralista, la gramática generativa y la lingüística de la enunciación. Y en segundo lugar La transparencia y la enunciación, de François Récanati, que a modo de una introducción a la pragmática, realiza un recorrido por los aportes que la filosofía del lenguaje y la lingüística han brindado para pensar diferentes problemáticas: el signo, la representación, la reflexividad lingüística y la intencionalidad.

3.

Más allá de la intencionalidad que se le pueda atribuir a cada uno de los volúmenes, o de la actuación que se pueda interpretar que realizan aisladamente tanto dentro como fuera del campo disciplinar, hay una dimensión que debe tenerse en cuenta: la intencionalidad del total de la colección, la fuerza ilocutiva de la decisión editorial completa. La autoría de ese total de los volúmenes se reconoce en el rol de la editora, Elvira Narvaja de Arnoux, que funciona, si bien no como escritora de cada tomo, sí como quien pone en sistema el conjunto de los volúmenes, que seleccionó, de hecho, qué títulos fueron parte de la colección y qué títulos no, configurando a partir de ellos el dispositivo "colección», e interviniendo en una serie de teorías que se reconfiguran y toman otro sentido y otro potencial en el contexto argentino.

Es de la colección como objeto singular, con todos los volúmenes en su interior, de donde creemos que emerge un programa para la renovación de la lingüística, conformado por los distintos aspectos que intentamos ejemplificar a lo largo del trabajo: por un lado, los programas explícitos de cada marco teórico en sus indagaciones particulares frente al recorte que realizan del objeto lengua o lenguaje; por otra parte, la puesta en funcionamiento de una lingüística que interviene en el contexto, sea para actuar directamente sobre él o sea para dar las herramientas que permitan entender los fenómenos que lo atraviesan; y finalmente, la inscripción dentro del mismo programa de renovación, de la historiografía de la lingüística como parte interna de la disciplina.

La colección como macro acto de habla en su totalidad, va a actuar tanto hacia adentro como hacia afuera de la disciplina, recogiendo la intencionalidad de pensar el lenguaje en el modo en que construye e interactúa con lo social, y de pensar la lingüística en su historia y en la propia construcción de su objeto de estudio.

La relevancia del programa que emerge de la colección, debiera articularse con el rol de los distintos actores de la disciplina, como es el caso de Lavandera o Narvaja de Arnoux, así como del modo en que la lingüística y sus ramas fueron institu- 
cionalizadas y enseñadas en la universidad Argentina. Sería interesante, además, poder reflexionar sobre si efectivamente se puede hablar de una incidencia en las ideologías lingüísticas dominantes.

Finalmente, hay que hacer énfasis en que si bien es cierto que una colección de libros responde en parte a una lógica editorial, la lógica de un tipo de industria y su correspondiente mercado, lo que interesa es esa parte menos evidente de la idea de colección, ese modo en que como un dispositivo portador de discursos, crea un potencial de actuación en el contexto, de la mano de un rol autoral que dispone el modo en que se organizan los discursos individuales en la colección, es decir, construye el dispositivo.

\section{Referencias bibliográficas}

Altman, C. (2009). Retrospectivas e perspectivas da historiograf do lingüística no Brasil. Revista argentina de historiografia lingüistica, I (2). Barrenechea, A.M. et al. (1979). Estudios lingüisticos y dialectológicos. Temas hispánicos. Buenos Aires: Hachette.

Ducrot, O. (1984). El decir y lo dicho. Buenos Aires: Hachette.

Fuchs, C. y Le Goffic, P. (1970). Introducción a la problemática de las corrientes lingüisticas contemporáneas. (Traducción al español: Elvira Narvaja de Arnoux). Buenos Aires: Hachette.

MenèndeZ, S.M. (2013). Ana María Barrenechea y las teorías lingüísticas: una tensión constante. Exlibris, revista del Departamento de Letras $F F y L-U B A, 2,17-25$.

Múgica, N. y Solana, Z. (1989). La gramática modular. Buenos Aires: Hachette.

Narvaja de Arnoux, E. (2006). Análisis del discurso. Modos de abordar materiales de archivo. Buenos Aires: Santiago Arcos Editor.

Lavandera, B. (1984). Variación y significado. Buenos Aires: Hachette. Kerbrat-Orecchioni, C. (1986). La enunciación. De la subjetividad en el lenguaje (Traducción al espańol: Gladys Anfora y Emma Gregores). Buenos Aires: Hachette.

Recanatí, F. (1981). La transparencia y la enunciación. Introducción a la pragmática (Traducción al español: Cecilia E. Hidalgo). Buenos Aires: Hachette

Rubio Scola, V. (2014). A recepçao da análise do discurso na Argentina durante a «normalizaçao democrática»: o caso da UBA. Disertación presentada en el programa de posgrado en lingüistica de la Universidad Federal de Sao Carlos como parte de los requisitos para la obtención del titulo Maestría en Lingüistica.

SAID, E. (2004). El mundo, el texto y el crítico. Buenos Aires: Debate. SKINNER, Q. (2007). Lenguaje, politica e historia. Buenos Aires: Editorial Universidad Nacional de Quilmes.

SWIGgers, P. (2009). La historiografía de la lingüística: apuntes y reflexiones. Revista argentina de historiografia lingüistica, I (1). 
Vallejos, O. (2013). Enseñanza de la Lengua y la Literatura. Historia y Epistemología de la Lingüistica. Santa Fe: Ediciones UNL.

(2014). La constitución del espacio de la lingüística en la Universidad Argentina Período 1940-1966. Comunicación a las IV Jornadas de Historia de la Universidad Argentina. Universidad de Mar del Plata. et al. (2012). La renovación de la enseñanza de la lingüística en

la refundación democrática: la construcción de una nueva experiencia cognitiva en las clases de Lingüística General de Beatriz Lavandera en la UBA. Comunicación presentada en la 1 Jornada Internacional de Historia de la Lingüística - UBA.

\section{Ternavasio, Federico}

«La renovación de la lingüística en Argentina: un es- 
